FORUM

\title{
Year Zero for the Archaeology of Iraq
}

\author{
Roger Matthews \\ Reader in Archaeology of Western Asia \\ Institute of Archaeology, UCL
}

\section{Disaster and Opportunity}

The heritage of Iraq, ancient Mesopotamia, has suffered devastating blows in recent months, and continues to suffer at a truly grievous level. The looting of the Iraq Museum in Baghdad and of other regional museums, as well as ongoing illicit digging at archaeological sites, particularly in the south of the country, are steadily depleting a rich and varied heritage resource that can be matched in value and historical significance by few countries in the world. Through extensive coverage in press and web-site media (e.g. Brodie 2003; Fisk 2003), these events are known to all and are almost universally condemned as appalling, the more so when viewed as probably avoidable.

In this paper I do not propose to cover once more the ground of what happened in Iraq during those few days in April 2003 when the Iraq Museum fell prey to wreckers and looters as the regime of Saddam Hussein collapsed. Much ink has been spilt on this subject and there is little more to add unless and until fresh evidence appears (for a recent summary see Lawler 2003). Nor do I wish to consider in detail ways in which scholars and interested parties of the world might assist our Iraqi colleagues in the long and arduous task of repairing damage done to buildings, sites and artefacts caught in the crossfire of war. There are many better qualified than I to tackle that subject, and they are already bending their skills and energies to that end in difficult and dangerous circumstances.

What I wish to discuss here is the broader and longer-term question of how the archaeology of Iraq, as a practice and as an academic discipline, might develop in the years ahead. The archaeology of Iraq, once one of the most thriving and vibrant regional archaeologies of the world, is perforce in disarray, and it is little exaggeration to say that the discipline must start again from Year Zero. Here I argue that while participating in the universal mourning for the terrible losses and setbacks suffered by the heritage of Iraq, we should at the same time strive to take advantage of a unique opportunity to start afresh in our academic engagement with the discipline of Mesopotamian archaeology. We are now at liberty to reformulate a discipline that has developed in a largely haphazard fashion over the past 150 years, principally in contexts of imperial exploitation, colonial administration, and more recently, post-colonial angst (Bahrani 1998; Matthews 2003). We are free, should we wish, to turn our backs on that past, while perhaps appreciating its achievements, and to construct a new framework for the future. What then might be a manifesto for a new archaeology in Mesopotamia?

It is likely to be some time before foreign archaeologists return en masse to work in Iraq. Following a long period of disciplinary development, particularly in the period between 1950 and 1990, the years following the Iraqi invasion of Kuwait and the 
subsequent war of 1991 saw an almost complete collapse of the practice of archaeology in Iraq by western scholars - with some exceptions. The current breakdown in security through much of the country is likely to exclude an imminent rebirth of the discipline as a practical exercise. There is, nevertheless, wide scope for the formulation of a new archaeology of Iraq in terms of a framework for future practice, and this paper represents a tentative step in that direction. Here I consider several key areas where there needs to be significant changes and developments if the archaeology of Iraq is to survive and thrive as a practical, academic and politically valuable discipline in the years ahead.

\section{The Significance of the Mesopotamian Past - A Disjunction}

I wish to commence by considering the global value frequently assigned to the heritage of Iraq. In addition to the countless newspaper articles of recent months, several books and papers have appeared in the past few years proclaiming the unique significance of the Mesopotamian past for the cultural traditions of the West and the world at large (Bottéro et al. 2000; Dalley 1998; Parpola 2000). There seems, however, to be a serious disjunction between these avowals and other conventional markers of global significance, as is instantly clear if we look at the UNESCO World Heritage List of cultural properties, comprising 754 sites in a total of 128 states around the world (World Heritage List 2003).

Of these sites, 582 are cultural, 149 are natural and 23 are combined cultural and natural. A total of 141 of the sites on the World Heritage List are found in only five states of western Europe (France - 26; Germany - 26; Italy - 35; Spain - 34; UK - 20). In Iraq there are only two listed sites, the desert town of Hatra and the Assyrian city of Ashur, the latter added to the list as recently as this year. Other states of western Asia fare little better (Afghanistan - 2; Iran - 4; Israel - 3; Jordan - 2; Syria - 4; Turkey - 7). The criteria for inclusion of a site on the list allow for "archaeological sites which are of outstanding universal value from the historical, aesthetic, ethnological or anthropological points of view" (World Heritage List 2003), a broad remit within which scores of Iraqi sites would suitably sit. Here is not the occasion to explore in detail the politics of how heritage sites are nominated for inclusion on the World Heritage List, nor the question of how such a list can appear to be so heavily skewed towards the Eurocentric tradition. The point here is merely to hint that despite academic and public avowals of the importance of the Mesopotamian past in global terms, there is evidence to suggest that this significance is not fully appreciated in quarters where it may matter greatly. Few archaeologists would gainsay the right of sites such as Uruk-Warka, Ur, Babylon, Nimrud and Nineveh, amongst many others, to inclusion on the World Heritage List, and it is to be hoped that future years will see a swing in this direction, even if the signs are not immediately promising.

A similar disjunction can be detected if we look at education in UK schools where, again despite standard pedagogic views of Mesopotamia as the 'cradle of civilisation', there is an appalling lack of attention devoted to study of the heritage of western Asia in general and Iraq in particular (see Matthews 2003: 193-197 for more on Mesopotamia and education in UK schools). Again the point here is not to consider this issue in 
detail, merely to highlight a disparity between avowed significance and realised significance in practice. If we want to view Iraq as the 'cradle of civilisation' and its ancient societies as ancestors of the West in terms of religion, science, philosophy, literacy and urban life, then perhaps we should be doing more to ensure its study and appreciation in the public arenas of our lives, including schools and the UNESCO World Heritage List. Lobbying the cause of the archaeology of Iraq, then, is a task that needs considerably increased attention from those who know and care.

\section{Communication and Interaction - A Further Disjunction}

A connected point is that of communication, a topic that needs consideration in both local and global terms. At the local level, there needs to be significant progress in the ways in which archaeology and archaeological projects are integrated within their host country. Past practice in the archaeology of Iraq has been for professional teams to spend restricted periods of time in the field, either excavating at specific sites or surveying specific regions, fulfilling their field objectives before departing as abruptly as they arrived. These teams appear in the field like aliens from another planet, their impact on local communities rarely considered within an overall project strategy except as regards the necessary budget item of wages for local workers. The archaeological project is divorced from its present physical context, the disjunction between past and present realities unbridged across a chasm of communication. The past is viewed as global, relevant and scientific, the present as local, neutral and detached. In light of this disjunction, imposed and maintained by scholars from the West, we need hardly be surprised to learn that local communities appear to feel little connection with the ancient past of their own country (Potts 1998: 195). What interest and involvement have they had in constructing that past, and what attempts have been made to integrate their own senses of the past with that imposed from outside? Future archaeological interactions in Iraq will require programmes of local integration for all field projects. These programmes may include elements such as illustrated literature in Arabic for distribution to nearby towns and villages, education sessions in local schools, appreciation of views and histories of the local past, and above all a concern both to situate archaeology within the local scene and to incorporate the local scene into an archaeological framework of practice and knowledge.

Needless to say, these approaches to integration require skills in communication, in particular a familiarity with local languages and customs. Anyone seriously contemplating archaeological fieldwork in Iraq should learn Arabic, preferably Iraqi Arabic, just as anyone from abroad considering digging in Britain with the Museum of London Archaeology Service (MoLAS) needs to learn English. There are plenty of courses, books and tapes available, even for Iraqi Arabic (e.g. Erwin 1969), and there is no acceptable excuse for project directors - and other staff - not to have a good working knowledge of the language of their host country. In addition to learning local languages, archaeologists working in Iraq need to learn and respect local customs, a lifelong process of interacting directly and indirectly with people and traditions.

At the global level there are several issues to consider. A major concern is that of publication. The duty of professional archaeologists to publish their findings in a prompt 
and full manner is accepted by all, in theory. In practice a great many excavated sites and projects remain inadequately published. Iraq has suffered more in this regard than most countries of the world. Wave after wave of projects from the $20^{\text {th }}$ century have not received appropriate publication, and some probably never will, as project directors depart this world taking vital knowledge with them. It is not only large-scale research projects that have so far failed in general to meet adequate publication standards. It is also the case that hosts of rescue surveys and excavations conducted in Iraq through the 1970s and 1980s in advance of dam construction remain largely unpublished, reservoirs of knowledge expensively accumulated and currently accessible only to a handful of privileged scholars and their research assistants. There needs to be a concerted effort to improve the publication record of projects in Iraq, coordinated at a national level at least. Academic bodies such as the British School of Archaeology in Iraq (BSAI), itself a sponsor of numerous field projects in Iraq over the years, need to acquit their publication obligations more fully and promptly. It is disappointing that throughout the 1990s, when British fieldwork in Iraq was not possible, the BSAI did not more forcefully seize the opportunity to devise, finance and implement a concerted programme of publication of all projects undertaken in previous years with BSAI support, as it was encouraged to do by its main funding source, the British Academy. It is still not too late, but there needs to be the will to commit resources at a scale significant enough to achieve meaningful results.

A related issue, once more, is that of language and communication. Even where projects are adequately published within an academic framework, in English, German, French or Italian, there has been little serious attempt to publish results in local languages, beyond brief summaries in Arabic appended to the main text (itself a commendable step in the right direction). The failure of scholars of the West to communicate their results in Arabic is another feature of the disjunction between past and present that has hitherto characterised the archaeology of Iraq. In his book The Crisis of Islam, Bernard Lewis cites results of the 2002 report on Arab Human Development, revealing that about 330 books are translated each year into Arabic and that since the $9^{\text {th }}$ century AD a total of some 100000 books has been translated into Arabic, a total that approximates the number of books translated into Spanish each year (Lewis 2003: 89, my emphasis). In other words, the Spanish-speaking world is receiving translated books at a rate 300 times that of the Arabic-speaking world. In per capita terms, each year one new book is translated into Arabic for every 600000 of the world's 200 million Arabic speakers, while one new book is translated into Spanish for every 3000 of the world's 300 million Spanish speakers. These figures relate only to books translated into Arabic or Spanish and do not take account of books published originally in either of those languages.

In addition to the undoubted duty of publication of field projects in English or another major language of the West, it does not seem unreasonable to suggest that western academics have an obligation to strive to improve the appalling statistics on translated Arabic publications outlined above. It is not solely a question of commissioning Arabic summaries of one's own projects, but more pressingly a need to encourage, allow and support the translation of hundreds and thousands of already existing volumes into Arabic for use in schools, universities and homes throughout Iraq and beyond. Nor is it a 
question of swamping Iraq with translated publications that will oblige Iraqi academics to engage with the West on the West's terms. It is rather a matter of providing Iraqis with evidence and interpretations in their own language(s) that can be used as a basis for agreement, disagreement and negotiation as local opinions and reactions evolve in a truly untrammelled atmosphere and are given the opportunity to contest the so far supreme interpretations of the West. This process will take years and decades. We should start soon.

\section{Past Concerns and Present Realities - A Final Disjunction}

Finally, I wish to return briefly to the point made earlier about the apparent disjunction between the past concerns of the archaeologist and the present realities of the host community/country. In the 1970s the comparative social statistician Rein Taagepera bemoaned how study and teaching of the past in the West was structured as a unilinear trajectory that starts with the rise of civilisation in western Asia before moving smoothly to Greece where the roots of our post-Renaissance world are seen to lie (Taagepera 1978: 123). This tradition totally ignores fundamental developments that took place in the worlds of Byzantium and Islam in the long period between the collapse of the Graeco-Roman world and the start of the modern European era.

Contemporary archaeology has not so far succeeded in modifying this trajectory and in fact has barely attempted the task. In the words of Philip Kohl, "an evolutionary archaeology of the ancient Near East has so far been conceptualized only within an Orientalist mode that distances present realities from past concerns" (Kohl 1989: 245). The past of Mesopotamia has in effect been hijacked to provide a basis, an origin, a source, for the evolution of the Eurocentric tradition in subsequent centuries. It is time now to cast away this outmoded and rather restricted manner of looking at the past, and time to allow the modern peoples of Iraq and western Asia to construct their own historical trajectories, whatever they may be and however difficult we in the West may find them to digest. Assistance to such an end may be provided by a greater emphasis in the West and within Iraq on the archaeology of the Islamic era of Iraq, exceptionally rich as it is in archaeological remains from that era.

In the immediate term, as current occupiers and administrators of the state of Iraq we should listen closely to the requests of Iraqi colleagues for assistance in re-establishing their shattered lives including, as regards heritage, the list of desiderata provided at a meeting in the British Museum, London, as early as $29^{\text {th }}$ April 2003. The compilers of this list, representatives of the Iraqi State Board of Antiquities (SBA), requested the Coalition Provisional Authority (then the Office for Reconstruction and Humanitarian Assistance) to restore staff numbers to the 1980s levels of 2600 staff country-wide, to provide equipment and facilities needed for smooth operation of the SBA and to provide a variety of other forms of material and financial assistance. Satisfaction of these requests has been difficult to acieve, and is likely to remain so until a sense of security settles once more on what was one of the most law-abiding, cosmopolitan and hospitable countries of the world, and whose contribution to global heritage has a truly unique significance. 


\section{References}

Bahrani, Z. 1998. Conjuring Mesopotamia: Lawler, A. 2003. Mayhem in Mesopotamia. Science Imaginative Geography and a World Past, in Meskell, L. (ed.) Archaeology Under Fire. Nationalism, Politics and Lewis, B. 2003. The Crisis of Islam. London: Heritage in the Eastern Mediterranean and Middle East. London: Routledge, 159-174.

Matthews, R. J. 2003. The Archaeology of Mesopotamia. Theories and Approaches. London: Routledge.

Bottéro, J., Herrenschmidt, C. and Vernant, J. -P. (eds.) 2000. Ancestor of the West. Writing, Reasoning, and Religion in Parpola, S. 2000. The Mesopotamian Soul of Western Mesopotamia, Elam, and Greece. Culture. Bulletin of the Canadian Chicago: University of Chicago Press. Society for Mesopotamian Studies 35, 29-34.

Brodie, N. 2003. Spoils of War. Archaeology 56(4), 16-19.

Potts, D. T. 1998. The Gulf Arab States and their Archaeology, in Meskell, L. (ed.) Archaeology Under Fire. Nationalism, Politics and Heritage in the Eastern Mediterranean and Middle East. London: Routledge, 189-199.

Erwin, W. M. 1969. A Basic Course in Iraqi Arabic. Washington D.C.: Georgetown University Press.

Taagepera, R. 1978. Size and Duration of Empires: Systematics of Size. Social Science Research 7, 108-127.

Fisk, R. 2003. Raiders of the Lost Iraq. The Independent (Review section) $3^{\text {rd }}$ June 2003, 2-5.

World Heritage List 2003. [http://whc.unesco.org/ nwhc/pages/doc/mainf $3 . \mathrm{htm}$ ] [Accessed: 21.09.2003]

Material Culture of the Modern Era in the Ancient Orient: Suggestions for Future Work, in Miller, D., Rowlands, M. and Tilley, C. (eds.) Domination and Resistance. (One World Archaeology 3) London: Unwin Hyman, 240-245. 